\title{
A IMPORTÂNCIA DA TAXA DE JUROS NA OBTENÇÃO DE RECURSOS FINANCEIROS PELO MICROEMPREENDEDORBRASILEIRO
}

\author{
Edineide Maria de Oliveira* \\ Natalie Burgardt Ferreira**
}

\begin{abstract}
RESUMO: A proposta deste trabalho foi estudar a importância da taxa de juros na obtenção de recursos financeiros pelo microempreendedor brasileiro, no período de três anos, compreendidos de 2015 a 2017, destacando a variável macroeconômica, taxa de juros, que é importante tanto na liberação de crédito pelas instituições financeiras, quanto nos juros embutidos em pagamentos de empréstimos. Foram pesquisadas políticas para facilidade de crédito, que permitem que às microempresas com dificuldades de acesso a financiamentos externos consigam, além de boas práticas administrativas, a sobrevivência no mundo corporativo. Utilizou-se um estudo bibliográfico com autores consagrados no tema. Por meio de análises feitas com base em levantamento de dados reais de tabelas informativas e gráfícos, foi possível verificar as dificuldades impostas pela burocracia na obtenção de financiamento externo, que levam o microempreendedor a não investir no negócio. Somam-se a essas dificuldades, o fato de as instituições bancárias não disporem de linhas de crédito mais acessíveis aos pequenos microempreendedores individuais.
\end{abstract}

Palavras-chave: taxas de juros, empreendedores, empresas brasileiras, instituições financeiras, investidores.

\begin{abstract}
The purpose of this study was to study the importance of the interest rate in obtaining financial resources by the Brazilian microentrepreneur, in the period of three years, from 2015 to 2017, highlighting the macroeconomic variable, interest rate, which is important both in the release of credit financial institutions, as well as interest rates embedded in loan payments. Policies for credit facility were researched, which allow microenterprises with difficulties in accessing external financing to obtain, in addition to good administrative practices, survival in the corporate world. We used a bibliographic study with authors devoted to the theme. Analyzes made based on real data collection of information and graphical tables, it was possible to verify the difficulties imposed by the bureaucracy in obtaining external financing, which lead the microentrepreneur not to invest in the business. Added to these difficulties is the fact that banking institutions do not have credit lines that are more accessible to small individual microentrepreneurs.
\end{abstract}

Key words: interest rates, entrepreneurs, Brazilian companies, financial institutions, investors.

*Doutora em Ciências e mestra em Ciências da Educação e Administração pela PUC SP. Economista, Especialista em Educação Matemática e Ensino Superior. Coordenadora e docente do UNIFAI - Centro Universitário Assunção.

** Graduada em Administração pelo UNIFAI - Centro Universitário Assunção. 


\section{INTRODUÇÃO}

O presente trabalho buscará apresentar qual a importância da taxa de juros na obtenção de recursos financeiros pelo microempreendedor brasileiro. No Brasil, desde os tempos mais remotos, a grande população brasileira possui certa dificuldade em conciliar a política econômica e seu cotidiano. Dessa forma, alguns empreendedores também enfrentam esse tipo de dificuldade quando estão gerenciando setores de empresas, principalmente às microempresas, que não expressam recursos vastos para treinamento e formação de seus gestores. Sendo assim, este artigo pretende expressar a importância de uma variável macroeconômica como a influência da taxa de juros na atuação de empresas de microporte no Brasil.

Para os microempreendedores é fundamental contar com um especialista no setor financeiro da empresa, capaz de acompanhar as oscilações da economia de forma a não ser surpreendido pela alta da taxa de juros e suas consequências. Portanto a problemática deste estudo consiste em verificar como a taxa de juros influencia na obtenção de recursos financeiros pelo microempreendedor brasileiro. Para tanto, foram formuladas quatro hipóteses, que poderão ser confirmadas ou refutadas. Segundo Assaf Neto (2011):

1. Quando as taxas de juros estão altas, a propensão a conseguir empréstimos é menor;

2. Quando as taxas de juros estão baixas, a propensão a conseguir empréstimo é maior;

3. Taxa de juros elevada, maior a taxa de mortalidade das microempresas;

4. Taxa de juros menor, cresce número de MEIs (Microempreendedores Individuais).

Desta forma, o objetivo geral do estudo é apresentar a importância da taxa de juros e sua influência sob as instituições financeiras na liberação de crédito ao microempreendedor.

Os objetivos específicos são demonstrar quais fatores causam as oscilações da taxa de juros Selic; mostrar como as variações da taxa Selic influenciam as microempresas; e apresentar como os microempreendedores podem obter crédito de forma menos burocrática.

Assim sendo, este trabalho se justifica porque pretende demonstrar as dificuldades em obter crédito pelo microempreendedor e os benefícios de um plano de negócios. O procedimento metodológico utilizou pesquisa do tipo exploratória com autores especialistas no tema.

A primeira parte do artigo apresentará um histórico da taxa de juros no mundo e depois no Brasil, abordará também o que é o spread bancário e o que ele representa no cenário 
financeiro de crédito. Em seguida, traçará um panorama das microempresas no Brasil com recorte nos índices de falências (causas) requeridas e decretadas. Posteriormente o estudo elucidará os aspectos financeiros das empresas, apresentando como a taxa de juros interfere no crédito às microempresas e tratará das opções que as empresas podem criar e buscar para evitar a falência ou endividamento precocemente. O trabalho é finalizado mostrando como os objetivos foram alcançados e a pesquisa, respondida, confirmando ou refutando as hipóteses elencadas. Também serão apresentadas as limitações, contribuições e recomendações para futuros trabalhos que busquem verificar a relação da taxa de juros com o microempreendedor.

\section{DESENVOLVIMENTO DAS TAXAS DE JUROS}

Desde a Grécia antiga, atividades de arrendamento de terras, de minas com metais preciosos ou empréstimos já eram assuntos que começavam a ser estudados e escritos, como apresentado na obra do historiador e soldado Xenofonte (355 a.C.), em Atenas, observando como mecanismos econômicos funcionavam, (MARTINS, 2013).

Segundo Pereira (1979), tanto a economia quanto a administração estudam a produção, circulação e distribuição de bens econômicos. Ambas são ciências que têm como preocupação fundamental os bens econômicos ou os recursos existentes em uma sociedade. No entanto é preciso quantificar essas transações com os recursos financeiros e a taxa de juros está presente nas transações financeiras.

Para Adam Smith, a taxa de juros é oriunda do juro resultante de uma fração do lucro do capital e que em matemática financeira tem a seguinte fórmula: $\quad J=C$.i. $n$

Onde Jé o juros; C é o capital; i é a taxa e n, é o período. (GASTALDI, 2005)

Keynes, após fazer várias críticas aos postulados clássicos, defendeu que a taxa de juros deve ser entendida como uma recompensa pela renúncia à liquidez. Ele faz alusão às diferenças entre taxa de juros e taxa de lucro, mostrando a distinção conceitual entre eficiência marginal do capital (taxa de lucro) e produtividade marginal do capital, que é o acréscimo na quantidade produzida, decorrente de um acréscimo no estoque de capital, não se relacionando diretamente com a taxa de juros e sim com a taxa de lucro. (KEYNES, 2012).

Assaf Neto (2003, p. 16) defende que a taxa de juros é o coeficiente que determina o valor do juro, isto é, a remuneração do fator capital utilizado durante certo período de tempo. A taxa de juros significa a porcentagem em cima de algo, uma exigência financeira para ceder crédito ou empréstimo, uma espécie de tributo e juros; é o valor acima do que foi cedido, como uma 
compensação pelo crédito que foi repassado a um terceiro, pessoa física ou jurídica. No Brasil a taxa de juros que o governo brasileiro paga por empréstimos tomados dos bancos é a taxa Selic (Sistema Especial de Liquidação e Custódia), determinada pelo Banco Central do Brasil (BCB) e definida pelo Comitê de Política Monetária (Copom), formado pelo presidente e por mais oito diretores do BCB. Trata-se de uma taxa média, calculada diariamente, que se paga por títulos públicos, ou seja, toda vez que se compra um título do governo, é como se houvesse um empréstimo para o governo brasileiro, a ser pago com base na Selic. A Selic se divide em duas: a primeira, a taxa Selic apresentada no parágrafo anterior; e a segunda, a taxa Selic Over, que é a taxa calculada referente aos empréstimos diários de bancos para bancos, quando existe um déficit, ou seja, maior saída perante a entrada de recursos, e a taxa Selic Meta, que é a que o presente trabalho tem a finalidade de apresentar (BACEN, 2016).

Caso a inflação aumente, devido crescente demanda que é provocada por diversos fatores político-econômicos, o Copom (Comitê de Política Monetária), órgão decisório da política monetária do Banco Central do Brasil, pode elevar ou diminuir a taxa de juros, com a intenção de que a procura por títulos aumente, pela vantagem de o juro estar maior e a demanda que está causando a inflação tenha um decréscimo, tentando assim equilibrar a economia nacional (ASSAF NETO, 2011).

Segundo o Portal do Empreendedor (2017), as microempresas normalmente têm poucos investidores e precisam essencialmente dos bancos e do crédito ofertado a taxas baixas de juros; quando existe a elevação de taxas e consequentemente de juros, as organizações passam a operar com recursos limitados.

Dados da Serasa Experian de 2016 mostram que naquele ano, o número de requerimentos de micro e pequenas empresas que fizeram requisição de falência é superior (em $56 \%$ ) ao das médias e grandes empresas. Percebe-se com esse percentual, que quanto menor o porte da empresa, mais difícil é a sua sobrevivência.

Segundo Keynes (2012), a taxa de juros se relaciona com a demanda do mercado versus os empréstimos, e movimenta a economia em um ciclo. Sendo assim, toda vez que a ocorre uma alta da taxa de juros, a taxa dos empréstimos feitos pelas instituições financeiras cresce para que haja lucro e, dessa forma, a pequena empresa é afetada, ao buscar crédito para fazer investimentos em equipamentos, funcionários, e tem prejudicado seu capital de giro. Sendo assim, a problemática do artigo é respondida parcialmente e a hipótese número um é confirmada, pois, quando as taxas de juros estão altas, a propensão em conseguir empréstimos é menor, visto que, os juros empregados nas parcelas de empréstimos aumentam conforme a elevação da taxa básica de juros. 


\section{TAXAS DE JUROS NO BRASIL}

De acordo com Assaf Neto (2011), a taxa Selic é nominal, ou seja, aponta os efeitos da inflação em determinado período. Já a taxa real de juros não leva em conta a inflação, por isso é menor que a Selic.

Ainda de acordo com o Assaf Neto, professor que estuda administração de finanças corporativas no Brasil:

Quanto mais baixa se situar a taxa de juros, maior se apresenta a atratividade dos agentes econômicos para novos investimentos, inclusive selecionando aqueles de maior maturidade. Para uma empresa, a taxa de juros reflete o custo de oportunidade de seu capital passivo, ou o preço a ser pago pelos recursos emprestados (ASSAF NETO, 2011).

Verifica-se que o autor mostra a resposta da problemática e a confirmação da hipótese número dois, ou seja, quando as taxas de juros estão baixas, a propensão a conseguir empréstimos é maior - a oferta de financiamentos aumenta quando os juros são menores, já que é mais rentável aos bancos aproveitar os lucros de pagamentos das parcelas dos financiamentos.

Nos países desenvolvidos, como Estados Unidos, Alemanha, Suécia, existe a relação entre desenvolvimento do sistema financeiro, com boas condições de crédito e bem-estar social. Porém, no Brasil, a realidade é que tanto as pessoas físicas, quanto a maioria das empresas, quando conseguem fazer empréstimos, pagam taxas de juros altas. Em 2016, a taxa de juros real (descontada a inflação) chegava aos 40,4\%, segundo o Banco Mundial (World Bank). Existem diversos fatores para que as taxas sejam tão altas, entre eles estão uma combinação de decisões do Banco Central, destinação de crédito, comportamento compulsivo dos bancos, ineficiência jurídica e inadimplência (BACEN, 2016).

No final de 2016, a taxa básica de juros iniciou um movimento de queda e chegou ao seu índice mais baixo no primeiro trimestre de 2018. Com os juros em níveis menores, houve uma reação positiva nas atividades dos micro e pequenos e inclusive o surgimento de novos microempreendedores. Uma combinação de fatores, como boas safras de alimentos, levou ao controle da inflação e a uma queda da moeda norte-americana, o dólar. Depois de uma pequena alta no fim do ano passado (2018), por causa dos reajustes dos combustíveis, os índices voltaram a cair no início deste ano. O recuo foi motivado também por novas quedas nos preços dos alimentos e dos serviços, setor ainda afetado pela demora na recuperação da economia. Assim, com a queda da inflação, a taxa de juros básica também começou a cair, porém, isso 
não significou queda significativa nos juros cobrados pelos bancos, em empréstimos e produtos bancários. Para elucidar a situação, a figura realizada pelo Copom a seguir mostra a trajetória da taxa de juros.

FIGURA 1 - TAXA DE JUROS NO PERÍODO DE TRÊS ANOS (de 2015 a 2017)

\begin{tabular}{|c|c|c|}
\hline Data & Perído de vigência & Taxa Selic \\
\hline $07 / 02 / 2018$ & $08 / 02 / 2018-21 / 03 / 2018$ & 6,65 \\
\hline $06 / 12 / 2017$ & $07 / 12 / 2017-07 / 02 / 2018$ & 6,90 \\
\hline $25 / 10 / 2017$ & $26 / 10 / 2017-06 / 12 / 2017$ & 7,40 \\
\hline $06 / 09 / 2017$ & $08 / 09 / 2017-25 / 10 / 2017$ & 8,15 \\
\hline $26 / 07 / 2017$ & $27 / 07 / 2017-06 / 09 / 2017$ & 9,15 \\
\hline $31 / 05 / 2017$ & $01 / 06 / 2017-26 / 07 / 2017$ & 10,15 \\
\hline $12 / 04 / 2017$ & $13 / 04 / 2017-31 / 05 / 2017$ & 11,15 \\
\hline $22 / 02 / 2017$ & $23 / 02 / 2017-12 / 04 / 2017$ & 12,15 \\
\hline $11 / 01 / 2017$ & $12 / 01 / 2017-22 / 02 / 2017$ & 12,90 \\
\hline $30 / 11 / 2016$ & $01 / 12 / 2016-11 / 01 / 2017$ & 13,65 \\
\hline $19 / 10 / 2016$ & $20 / 10 / 2016-30 / 11 / 2016$ & 13,90 \\
\hline $31 / 08 / 2016$ & $01 / 09 / 2016-19 / 10 / 2016$ & 14,15 \\
\hline $20 / 07 / 2016$ & $21 / 07 / 2016-31 / 08 / 2016$ & 14,15 \\
\hline $08 / 06 / 2016$ & $09 / 06 / 2016-20 / 07 / 2016$ & 14,15 \\
\hline $27 / 04 / 2016$ & $28 / 04 / 2016-08 / 06 / 2016$ & 14,15 \\
\hline $02 / 03 / 2016$ & $03 / 03 / 2016-27 / 04 / 2016$ & 14,15 \\
\hline $20 / 01 / 2016$ & $21 / 01 / 2016-02 / 03 / 2016$ & 14,15 \\
\hline $25 / 11 / 2015$ & $26 / 11 / 2015-20 / 01 / 2016$ & 14,15 \\
\hline $21 / 10 / 2015$ & $22 / 10 / 2015-25 / 11 / 2015$ & 14,15 \\
\hline $02 / 09 / 2015$ & $03 / 09 / 2015-21 / 10 / 2015$ & 14,15 \\
\hline $29 / 07 / 2015$ & $30 / 07 / 2015-02 / 09 / 2015$ & 14,15 \\
\hline $03 / 06 / 2015$ & $04 / 06 / 2015-29 / 07 / 2015$ & 13,65 \\
\hline
\end{tabular}

Nota-se que no Brasil as taxas de juros estão entre as mais altas do mundo, tanto a nominal quanto a real. A figura 1 demonstra como a taxa Selic era uma das mais altas do mundo em 2015 e como caiu nos últimos três anos (BACEN, 2018). 
Segundo dados do SEBRAE (2013), as microempresas representaram 27\% do PIB brasileiro, mais do que um quarto, com grande significância para o País. Essa informação mostra o quanto o Brasil depende desse tipo de empresa para alavancar seu crescimento. $\mathrm{O}$ empreendedorismo é fundamental para que a economia cresça e se firme no cenário econômico mundial.

Vigorando desde 01 de janeiro de 2018, a nova taxa de juros do BNDES, a TLP, sigla que significa Taxa de Longo Prazo, foi criada por meio da Lei 13.483 de 21 de setembro de 2017. Concebida durante a reestruturação do BNDES, após inúmeros casos de ligações com empresas com ações comprovadas de corrupção, a TLP é usada em empréstimos pelo Banco Nacional de Desenvolvimento Econômico (BNDES), agente do desenvolvimento empresarial. Foi criada para substituir a Taxa de Juros de Longo Prazo (TJLP), que era estabelecida a cada três meses pelo Governo com base na meta estipulada pelo COPOM, então, sua definição causava muitas incertezas.

A criação da TLP objetiva ter transparência e possibilidades de ampliar a prestação de garantias ou fianças e a realização de operações de securitização, ou seja, negociando créditos

junto a outras instituições ou investidores, buscando taxa mais baixa, composta de uma parcela de juros reais prefixados, juntamente com o índice de inflação (IPCA). O que vai definir a TLP é o Índice de Preços ao Consumidor Amplo (IPCA), mais a taxa de juro real da NTN-B de cinco anos. A convergência da TLP para a taxa de juro real da NTN-B será gradativa, acontecendo em cinco anos. Os valores da TLP no ano de 2018 sendo a.a.\%, foram de janeiro a maio, consecutivamente: $2,55 \%, 2,62 \%, 2,71 \%, 2,74 \%$ e 2,70\% (BNDES, 2018).

\section{SPREAD BANCÁRIO}

A palavra spread, de origem inglesa, significa espalhar ou propagar, mas no caso do spread bancário seu significado é outro, se trata da diferença entre a taxa de captação e a taxa de empréstimo, ou seja, é a diferença dos juros que o banco paga para captar dinheiro e o que ele cobra do correntista. Quando a taxa Selic está em alta, as instituições financeiras optam por emprestar seu capital ao governo, pois os juros pagos serão maiores, já que a Selic é a média de juros que o governo paga por empréstimos tomados junto aos bancos e assim o financiamento que as pequenas empresas buscam fica reduzido, quando a taxa está baixa é mais interessante emprestar aos clientes correntistas (BACEN, 2017).

De uma forma simples, o spread bancário é o lucro, porque decorre do empréstimo que a instituição financeira fornece ao cliente e nessa negociação o banco cobra uma taxa. Difere 
quando o banco faz a captação do dinheiro, a qual advém dos clientes bancários pela concepção de produtos e investimentos. Resumidamente o spread é o que faz com que os bancos obtenham seus maiores ganhos, "pois quando o banco empresta dinheiro ao cliente, cobra uma taxa pelo empréstimo - uma taxa que será certamente superior à taxa de captação. A diferença entre as duas taxas é o chamado spread bancário. (ASSAF NETO, 2011, p. 67)

Foi realizado um estudo pela FEBRABAN (Federação Brasileira dos Bancos), que apresentou dados de spreads bancários de 13 países e o Brasil ficou em primeiro lugar com $22 \%$, o segundo colocado 9,1 no México e 5,5\% na Alemanha.

FIGURA 2 - DEMONSTRATIVO DO SPREAD BANCÁRIO EM PERCENTUAL

\begin{tabular}{|c|c|}
\hline País & Spread em \% \\
\hline Brasil & 22 \\
\hline México & 9,1 \\
\hline Alemanha & 5,5 \\
\hline EUA & 5,2 \\
\hline Chile & 4,3 \\
\hline Índia & 4,0 \\
\hline Reino Unido & 4,0 \\
\hline Colômbia & 3,9 \\
\hline África do Sul & 3,9 \\
\hline Austrália & 3,3 \\
\hline Rússia & 2,7 \\
\hline Coréia do Sul & 2,5 \\
\hline Turquia & 2,1 \\
\hline
\end{tabular}

FONTE: A autora, a partir de dados da FEBRABAN (2016)

O que a FEBRABAN (2017) alega é que essa grande diferença do Brasil (mais da metade) para o segundo colocado, e dos demais países é que não se trata de lucro e sim de custo, devido à alta tributação, baixa concorrência e inadimplência. A taxa de inadimplência, no período de 2011 a 2016, foi de 55,7\%, sendo o item com maior parcela na composição do spread; em segundo lugar aparece o lucro com $23,3 \%$, e em terceiro aparecem os impostos e demais custos operacionais.

Segundo Marcelo Fiche (2015), os elevados spreads têm no Brasil um cenário de altas taxas cobradas para a intermediação financeira e de baixa relação crédito/PIB (a respeito do crescimento dos últimos anos), prejudicando o crescimento econômico do país. 
A Febraban pretende levar ao governo propostas para reduzir o spread bancário, e elevar o crescimento da economia brasileira, fazendo com o que capital chegue até as mãos das empresas brasileiras que precisam desse crédito para conseguir aumentar sua produção e seu giro de capital, necessário para que a empresa não entre em processo de falência (FEBRABAN, 2016).

Dowbor (2013) faz uma crítica às instituições financeiras com relação à taxa de juros, conforme a seguir:

\begin{abstract}
Os intermediários financeiros e rentistas não se contentam com a Selic, taxa de juros oficial sobre a dívida pública. Recorrem a um segundo mecanismo que é a fixação de elevadas taxas de juros ao tomador final, por bancos comerciais, mecanismo diferente da taxa Selic, tanto assim é que a mesma baixou radicalmente frente aos $25-30 \%$ da fase FHC para cerca de $8 \%$, sem que houvesse redução significativa dos juros dos bancos comerciais. (DOWBOR, 2013, p. 37).
\end{abstract}

Para Dowbor, os bancos não colaboram para a diminuição das taxas de juros cobradas em empréstimos para as pessoas físicas e jurídicas, dificultando assim o crescimento da economia:

\begin{abstract}
Como se trata de dinheiro do público confiado diretamente à gestão de intermediários financeiros, sem mediação do governo, poderíamos achar que não é desvio de dinheiro. De certa forma, quando tiram o nosso dinheiro sem a ajuda de um político, seria por assim dizer mais limpo. Habilidade de um lado, ingenuidade ou impotência do outro, mas não corrupção. Essencial para nós, é que sustentar no Brasil juros que são tipicamente dez vezes (dez vezes, não dez por cento a mais) relativamente aos juros praticados internacionalmente, só pode ser realizado mediante apoio político. E como durante longo tempo tivemos banqueiros na presidência do Banco Central, montou-se mais um sistema impressionante de legalização do desvio do nosso dinheiro. Esta "ponte", entre o político e o comercial, precisa ser explicitada (DOWBOR, 2013, p. 38).
\end{abstract}

Observa-se que o autor critica a atuação das instituições financeiras com relação aos juros cobrados no Brasil. Destaca que no artigo 170 da Constituição brasileira, existe a definição de princípios da ordem econômica e financeira, entre outros, a função social da propriedade e a livre concorrência. Destaca o artigo 173 parágrafo $4^{\circ}$, o qual "estipula que a lei reprimirá o abuso do poder econômico que vise à dominação dos mercados, à eliminação da concorrência e ao aumento arbitrário dos lucros."

No Brasil existem cerca de 150 instituições financeiras, enquanto que nos Estados Unidos chegam a cerca de 900, o que causa a falta de competitividade e a baixa nos preços dos juros na oferta de empréstimos para o microempreendedor (BACEN, 2018). A figura a seguir, tem como objetivo mostrar a diferença das taxas de juros praticadas no Brasil e demais países:

FIGURA 3 - TAXA ANUAL REAL DE JUROS SOBRE EMPRÉSTIMOS 


\begin{tabular}{|c|c|c|}
\hline Instituição & País & Juro real (em \%) \\
\hline \multirow{2}{*}{ HSBC } & ReinoUnido & 6,60 \\
\cline { 2 - 3 } & Brasil & 63,42 \\
\hline \multirow{2}{*}{ Santander } & Espanha & 10,81 \\
\cline { 2 - 3 } & Brasil & 55,74 \\
\hline Citibank & E.U.A. & 7,28 \\
\cline { 2 - 3 } & Brasil & 60,84 \\
\hline Banco do Brasil & Brasil & 25,05 \\
\hline Itaú & Brasil & 63,25 \\
\hline
\end{tabular}

FONTE: A autora, a partir de dados de Dowbor (2013, p. 39)

A tabela três, apresentada por Dowbor com dados fornecidos pelo IPEA - Instituto de Pesquisa Econômica Aplicada, com dados fornecidos pelas instituições bancárias citadas, mostra a diferença dos juros cobrados no Brasil e em outros países pelos mesmos bancos.

O Banco Central do Brasil criou projetos e regras desde 2017 para tentar diminuir o spread bancário. Uma dessas regras foi uma mudança no crédito rotativo de cartões de crédito, quando o cliente que opta pelo pagamento mínimo, só poderá o fazer uma vez, obrigando os bancos a cobrarem juros mais baixos dos clientes e já ofertarem a opção se parcelamento, evitando o endividamento contínuo dos clientes.

Outro projeto criado para ser implementado no início de 2018 é o Cadastro Positivo, em que dados de contribuintes ficam disponíveis para visualização, para que as instituições de crédito cobrem juros mais baixos e diminua a burocracia, facilitando a obtenção de recursos financeiros para microempreendedores, seja para abrir seu negócio próprio ou para ter capital de giro, objetivando a sobrevivência do negócio em períodos de crise ou de baixa rentabilidade.

Essas medidas existem para minimizar a falência das microempresas, que têm alta propensão a abrir requerimento para encerrar suas atividades.

\section{FALÊNCIA DAS MICROEMPRESAS}

Não são apenas as dificuldades econômicas os únicos empecilhos para a falta de êxito financeiro de microempresas. A falta de conhecimento e preparo dos empreendedores também é fator determinante. Um exemplo clássico narrado pelo Sebrae mostra que, ao perder o emprego formal ou estar fora do mercado de trabalho na área de atuação, uma alternativa é se 
tornar empresário, arriscando-se a ser um empreendedor, com o capital resultante da indenização (rescisão empregatícia) ou fazendo empréstimos como pessoa física - por desconhecimento de métodos mais apropriados para adquirir o crédito necessário, como pessoa jurídica.

No entanto, o lucro almejado não acontece devido ao despreparo e falta de conhecimento do negócio, pois para ser um empresário é necessário conhecimento em várias áreas, especificamente em administração, contabilidade, economia, direito e outras habilidades e competência que o negócio exigirá (SEBRAE, 2016).

A figura quatro mostra requisições de falências entre micro e pequenas, de médias e grandes empresas.

FIGURA 4 - REQUISIÇÕES DE FALÊNCIAS DE JUNHO A SETEMBRO 2015 E 2016

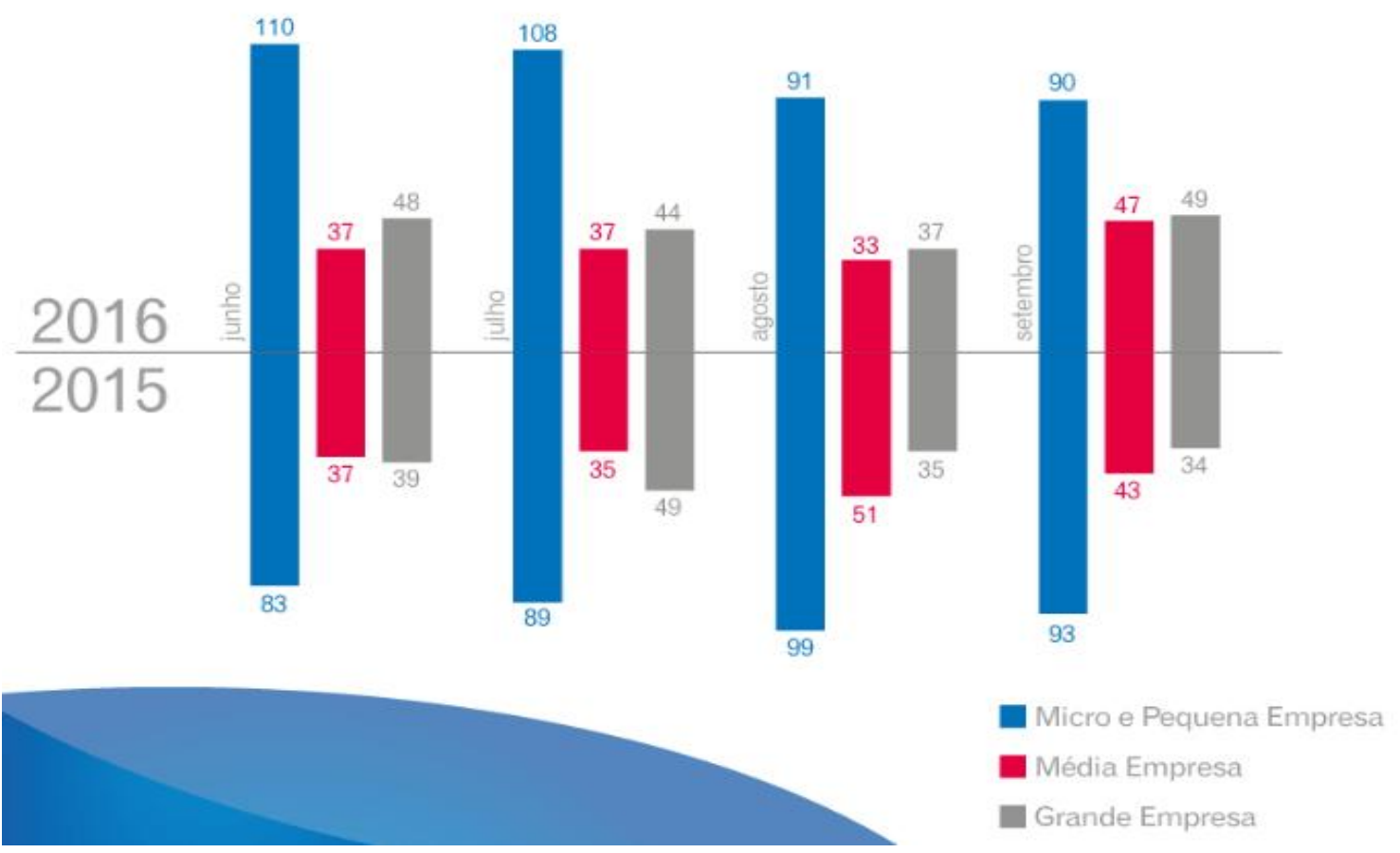

Fonte: (SERASA EXPERIAN, 2016)

A figura quatro apresenta um comparativo das aberturas de falências entre micro e pequenas, de médias e grandes empresas. As micro, pequenas e médias empresas têm um percentual de $54 \%$ e $56 \%$ em 2015 e $61 \%$ e $66 \%$ em 2016 acima das falências de médias e grandes empresas, respectivamente. 
Assaf Neto (2011), explica que com taxas de juros mais baixas, maior a segurança do micro e pequeno empreendedor para buscar crédito. Os altos juros pagos, representam para a empresa que o valor pago poderia ser mais bem aproveitado em bens e serviços em prol do crescimento da organização. Dessa forma, é necessário que haja a busca por alternativas de taxas de juros mais baixas, para melhor aproveitamento do capital passivo, evitando que aconteça a falência ou endividamento precocemente.

Segundo o Banco Central do Brasil (2010), normalmente, com baixo capital, a mão de obra contratada não tem qualificação suficiente, as ofertas do serviço ou produto não são oferecidas com preços atrativos para o consumidor e investe-se pouco em propaganda, no entanto, fica subentendido que este cenário contribui para o fechamento das empresas. No entanto, se houvesse conhecimento, habilidade, competência por parte dos gestores e linhas de créditos com taxas de juros adequadas, haveria a possibilidade de investimento em qualificação da mão de obra, em inovação e criatividade, com propaganda para que o microempreendedor tenha êxito em suas atividades.

As três principais causas de fechamento de microempresas são a falta de planejamento prévio, gestão empresarial deficitária e o comportamento do empreendedor. Verifica-se que dentro do planejamento prévio, a maior causa de fechamento das microempresas é a falta de estudo de mercado, com 46\%,e em segundo lugar, com 39\%, a falta de conhecimento sobre capital de giro e qual a sua necessidade para conseguir manter a empresa com fluxo financeiro ativo, ou seja, enquanto a empresa não consegue dar lucro por falta de clientes, ter recursos financeiros para manter o pleno funcionamento, evitando dívidas e arcando com responsabilidade o pagamento de seus custos e despesas, e com $38 \%$, a falta de conhecimento sobre a concorrência, com a falta de foco voltada para o negócio (SEBRAE, 2014).

De acordo com o artigo do BACEN (2017), a formalização dos Microempreendedores Individuais iniciou-se em 2009 e até março de 2017 existem cerca de 8,7 milhões de MEIs registrados na Secretaria Especial da Micro e Pequena Empresa (Sempe) do Ministério da Indústria. Desse total, foi constatado até dezembro de 2016 que apenas 19\% possuíam relacionamento bancário (contas em instituições financeiras) e $8 \%$ possuíam operações de crédito. A explicação para esse fato é que os microempreendedores utilizam contas como pessoas físicas e não jurídicas, pela facilidade ser maior em obter um empréstimo pessoal do que para sua empresa e, o principal, a taxa de juros é menor para a pessoa física. A dificuldade no crédito vem de outro fator decisivo, a inadimplência.

A inadimplência na pessoa jurídica chega próxima aos $18,5 \%$, quase duas vezes e meia maior que a inadimplência na pessoa física, que chega aos 7,6\% no Brasil. O valor de $R \$ 4,2$ 
bilhões é o crédito que foi cedido para os MEIs em 2016, e, em paralelo, para todas as pessoas físicas que possuem registro de MEI o valor cedido em crédito foi de $\mathrm{R} \$ 64,6$ bilhões, diferença que gira em torno de quinze vezes. Os números apresentados mostram as dificuldades reais na obtenção de crédito, pois necessitam de um prazo maior para quitar as parcelas.

$\mathrm{Na}$ busca de reduzir a falta de conhecimento para o microemprendedor, foram realizados diversos cursos, e diversos programas, mas destaca-se neste estudo o programa de microcrédito do governo federal chamado Progredir, que tem como objetivo incentivar a população de baixa renda, que faz uso de algum benefício do Bolsa Família, a ser microempreendedor e a não depender mais das bolsas que o programa Bolsa Família oferece, criando oportunidades de emprego e aumento na renda. Mesmo que se torne MEI, o cidadão ainda pode contar com os benefícios do Bolsa Família por até 2 anos. O programa tem como incentivo ao cidadão fornecer cursos gratuitos, objetivando a qualificação profissional, para tanto contempla disciplinas que explicam como se tornar microempreendedor, conhecendo a parte burocrática, administrando o negócio e fazendo o planejamento. O governo disponibilizará ao programa cerca de 3 bilhões de reais ao ano, como incentivo em microcrédito. O limite de empréstimo para cada solicitante fica nos 15 mil reais e é revertido para jovens de áreas urbanas ou rurais. São autorizados a operar o programa: o Banco Nacional de Desenvolvimento Econômico e Social (BNDES); Caixa Econômica Federal; agências de fomento; bancos comerciais; bancos de desenvolvimento; bancos múltiplos com carteira comercial; cooperativas centrais de crédito; cooperativas singulares de crédito; sociedade de crédito ao microempreendedor e à empresa de pequeno porte, e organizações da sociedade civil de interesse público.

Ainda de acordo com o site de notícias, G1, a estimativa de pessoas que poderão ser alcançadas pelo programa pode ir além das 13,4 milhões de famílias que recebem o Bolsa Família atualmente, já que há mais de 28,2 milhões de famílias inscritas no Cadastro Único, que é o requisito para que a família receba algum benefício em dinheiro do programa Bolsa Família. 


\section{REGISTRO DE NOVOS MICROEMPREENDEDORES}

Durante o período de 2015 a 2017, a quantidade do registro de MEIs (Microempreendedores Individuais) foi crescente, sendo de 3,7\% de 2015 para 2016, e de $10,62 \%$ de 2016 para 2017.

TABELA 5 - QUANTIDADE DE ABERTURAS REGISTRADAS DE MEIs

\begin{tabular}{llll}
\hline ANO & 2015 & 2016 & 2017 \\
\cline { 1 - 1 } TOTAL DE ABERTURAS & 1.491 .485 & 1.548 .950 & 1.733 .061 \\
\hline
\end{tabular}

Fonte: A autora, a partir de dados do SERASA EXPERIAN

A tabela cinco apresenta dados sobre o crescimento de registro das MEIs, coletados por meio da SERASA EXPERIAN. O crescimento é significativamente alto e, conforme análise feita pelos economistas do Instituto, se deve a crise política econômica que se instalou no País, quando aumentou o desemprego e refletiu lenta recuperação de empregos formais, ou seja, com grande número de pessoas sem emprego e com recursos de rescisões empregatícias, muitos enxergaram nas microempresas oportunidade de retornar ao mercado de trabalho, garantindo seu sustento. Grande parte dos que iniciaram um novo negócio acabou fechando por falta de estudo de mercado e de como manter a sobrevivência do negócio.

Conforme o SEBRAE, houve vários cursos e feiras com a finalidade de preparar o microemprendedor para conseguir realizar a gestão do seu negócio e saber as alternativas de créditos, como a Feira do Microempreendedor que ocorreu em São Paulo de 07 a 10 de abril de 2018, com várias palestras e expositores, para que, além de uma ideia, exista base para que se tenha sucesso na abertura e manutenção de uma microempresa. O próprio SEBRAE oferece ajuda na conquista do microcrédito, disponível no site da instituição, para que seja possível viabilizar o início de um negócio, que deve ter um plano estrutural para que seja aprovado.

\section{ALTERNATIVAS PARA OBTER RECURSOS FINANCEIROS}

Segundo o SEBRAE (2016), quando o microempreendedor individual (MEI) procura o crédito encontra certa dificuldade para conseguir. Algumas leis e programas, que foram 
aprovadas pelos governos estaduais e federais, estão incentivando instituições financeiras e ONGs (Organizações Não Governamentais), para que aumentem a oferta de linhas de créditos voltadas para o microempreendedor.

Segundo o Banco Central do Brasil (2010), com baixo capital para abrir seu empreendimento, a mão de obra acordada não é qualificada para a função para a qual é contratada e às ofertas do serviço ou produto, não são oferecidos com preços atrativos para o consumidor, além de investir pouco em propaganda. Em 2000 surgiram as primeiras Sociedade de Crédito ao Microempreendedor (SCM), que baseadas na lei 10.194 de 14 de fevereiro de 2001, conforme a seguir:

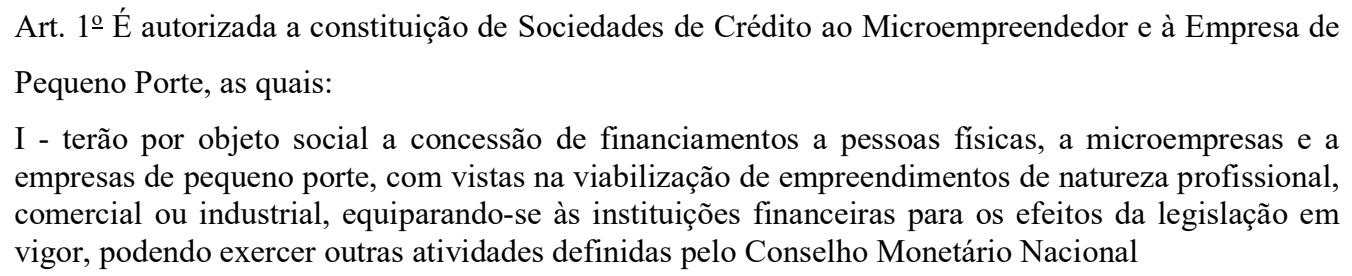

Fonte: (BRASIL, 2001).

Depois da criação das SCMs no final dos anos 90, houve parcerias de ONGs e governo, que contribuíram para a criação da Sociedade de Crédito a Micro Empresa de Pequeno Porte (SCMEPP), substituindo as SCMs, com o intuito de expandir o crédito às pessoas que realmente precisavam. Porém não houve adesão dos que realmente precisavam do dinheiro, por falta de conhecimento e divulgação. (BACEN, 2016).

Devido a não adesão à SCMEPP, o Banco do Brasil e a Caixa Econômica Federal passaram a trabalhar com microcrédito, com menores taxas de juros, porém valores pequenos, muitas vezes não suprindo a necessidade do empresário, como mostrado na entrevista com uma pequena empreendedora da cidade do Taboão da Serra, cidade da região metropolitana de São Paulo. Segundo a entrevistada, o dinheiro que o banco lhe emprestou não foi suficiente para que pudesse organizar seu próprio negócio em tempo considerável. Em tempo de crise políticoeconômica, o microcrédito deve ser praticado para que a economia não fique estagnada e volte a crescer. No ano 2010 existiam 36 SCMEPP, já em 2015 contava com sociedades ativas em 25 municípios de 13 estados.

Quando o microempreendedor individual (MEI) procura crédito consegue encontrar algumas facilidades no mercado, pois existem leis aprovadas pelo governo que incentivam as instituições financeiras a oferecerem linhas de créditos específicas para essa categoria. Para isso é necessário que haja estudo suficiente e de qualidade. 
Entre os grandes bancos, existe o BNDES (Banco Nacional de Desenvolvimento Econômico e Social), que foi fundado em 1952, sendo em 2018 um dos principais instrumentos do Governo Federal para ajudar no desenvolvimento de empresas de todos os portes e tem como sua missão apoiar empreendedores com crédito com menores juros e menos burocracia. Existem critérios para liberação do crédito, é fundamental que às micro empresas que desejam uma linha de crédito, apresentem um plano de negócios de acordo com a estrutura solicitada pelo BNDES, dessa forma é possível que o BNDES avalie as reais chances de sobrevivência e crie uma relação de confiança, dando credibilidade ao empreendedor, acreditando que sua empresa consiga pagar a dívida feita com empréstimos, no prazo acordado, nesse caso, o MEI - microempreendedor individual deve adquirir o cartão BNDES e em posse desse cartão, o microempreendedor deverá buscar linhas de crédito específicas para pequenos negócios (BNDES, 2017).

Outra alternativa para obter uma linha de crédito, para o microempresário do Estado de São Paulo é o programa Juro Zero Empreendedor, linha de crédito que vai oferecer empréstimos de até R\$ 20 mil para os empreendedores do Estado de São Paulo. O tempo para o pagamento do empréstimo é de 36 meses, com carência de seis meses. Esse programa conta com a parceria do SEBRAE, junto com a agência de fomento, Desenvolve SP, que possibilita que os microempreendedores graduados nos cursos do Sebrae tenham acesso a crédito com juro zero para obter capital de giro, para a compra de máquinas e equipamentos (SEBRAE, 2018).

A ONG Anjos Investidores, criada em 2011, por um empreendedor chamado Cassio Spina, conta com parceiros voluntários, que apoiam novos empreendedores que buscam empréstimos para iniciar microempresas e que não conseguiram empréstimos com instituições bancárias, devido à burocracia e altos juros pagos nas parcelas de seus empréstimos. $\mathrm{O}$ microempreendedor deve estar em contato e apresentar seu plano de negócios.

Todas essas alternativas fogem do caminho habitual do microempreendedor, que em um primeiro momento cogita buscar crédito nos grandes bancos, quando necessário para abrir ou manter o seu negócio. Por isso o planejamento prévio do negócio é fundamental, assim é possível conhecer ONGs e órgãos do governo que tenham como objetivo contribuir para a criação e manutenção da microempresa (SEBRAE, 2018).

\section{CONSIDERAÇÕES FINAIS}

O estudo possibilitou realizar apresentações de como as taxas de juros interferem ou não na existência de uma microempresa brasileira, questionando como a taxa de juros afeta a 
obtenção de crédito da microempresa no Brasil. Para tanto se verificou que a taxa de juros influencia significativamente na obtenção de crédito, pois quando as taxas de juros estão mais altas as instituições financeiras optam por investir seus recursos em títulos do governo, ao invés de disponibilizar créditos às microempresas, obtendo assim maiores ganhos e diminuindo os riscos, como o da inadimplência, por exemplo, no entanto para o microempresário o aumento na taxa básica de juros representa maior endividamento e pagamentos em parcelas maiores, comprometendo outras necessidades da empresa.

Sendo assim a primeira hipótese, que consiste em saber quando as taxas de juros estão altas, a propensão em conseguir empréstimos é menor se confirma, e portanto, essa hipótese foi aceita. No entanto, quando as taxas de juros estão baixas, a propensão em conseguir empréstimo é maior, pela oferta, então essa hipótese foi aceita. Na terceira hipótese, parte do trabalho relaciona a taxa de falência das microempresas com o crescimento das taxas de juros, o que foi comprovado não ser verdadeiro diante dos dados estatísticos da SERASA EXPERIAN, mostrando que $46 \%$ dos empreendedores inexperientes têm falência decretada por falta de planejamento prévio, que abrange a falta de estudo sobre o mercado e sobre quais as melhores opções para obter recursos financeiros, logo, a hipótese foi refutada.

A última hipótese foi refutada, pois taxas de juros menores, não está diretamente relacionada com acréscimo do número de MEIs (Microempreendedores Individuais), e sim com o despreparo no tocante a conhecimento do microempreendedor que optou por uma nova atribuição, devido à falta de trabalho, ou seja, o desemprego.

Desta forma, o objetivo geral foi alcançado, pois apresentou o conceito da taxa de juros, suas influências na obtenção do microcrédito e as alternativas aos microempreendedores para conseguir de forma mais rápida e menos burocrática o recurso financeiro de que precisa para abrir ou manter seu negócio.

Os objetivos específicos também foram atingidos, pois foram demonstrados quais são os fatores que causam as oscilações da taxa de juros Selic, definidas pelo COPOM para controle da inflação, para diminuir a quantidade de dinheiro em circulação, conter a expansão do consumo e do crédito; também entender como as variações da taxa Selic influenciam as microempresas, com a oferta maior ou menor de crédito pelos bancos. E por fim os microempreendedores podem obter crédito de forma menos burocrática, com alternativas possíveis e com poucas restrições.

As contribuições encontradas neste artigo são a verificação de dados da relação entre a dificuldade de obtenção de crédito pelo microempreendedor individual para investimento em 
sua empresa ou para capital de giro e a apresentação das taxas de juros e sua interferência nas microempresas.

As recomendações consistem em aprofundar os estudos sobre o tema e verificar as influências das taxas de juros no Brasil e como as microempresas se desenvolverão com a alta ou baixa dos juros, realizando estudo comparativo entre as taxas existentes e a sobrevivência e mortalidade de empreendimentos de micro porte.

\section{REFERÊNCIAS}

ANJOS DO BRASIL. História, missão e termos. Disponível em:

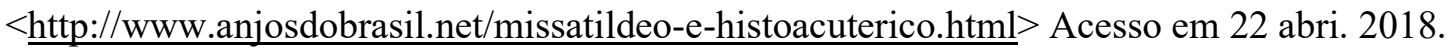
ASSAF NETO, Alexandre. Matemática financeira e suas aplicações. $8^{\mathrm{a}}$ ed. São Paulo: Atlas, 2013.

ASSAF NETO, Alexandre. Mercado financeiro. 10ª ed. São Paulo: Atlas, 2011.

BANCO CENTRAL DO BRASIL. Sociedades de Crédito ao Microempreendedor e à Empresa de Pequeno Porte. Disponível em: <http://www.bcb.gov.br/pre/composicao/scmepp.asp $>$ Acesso em: 17 nov. 2016.

BANCO CENTRAL DO BRASIL. Copom. Disponível em: $<$ http://www.bcb.gov.br/htms/copom_normas/a-hist.asp?idpai=copom $>$ Acesso em: 17 nov. 2016.

BANCO CENTRAL DO BRASIL. Panorama do Crédito Concedido a Microempreendedores Individuais. Disponível em: <https://www. bcb.gov.br/nor/ relincfin/serie cidadania_financeira_4_credito_concedido_mei.pdf $>$ Acesso em 07 maio 2018. BANCO CENTRAL DO BRASIL. Ilan Goldfajn. Painel: Projeto spread Bancário. Disponível em: $\quad$ https://www.bcb.gov.br/conteudo/home-ptbr/Textos Apresentacoes/Apresentacao_Painel_Projeto_Spread_Bancario.pdf $>$ Acesso em: 17 abr. 2018. BANCO MUNDIAL (WORLD BANK). Brasil: aspectos gerias. Disponível em: $<$ http://www.worldbank.org/pt/ country/brazil/overview> Acesso em: 13 abr. 2018.

BANCO NACIONAL DO DESENVOLVIMENTO. Taxa de juros de Longo Prazo. Disponível em: < https://www.bndes.gov.br/wps/portal/site/home/financiamento/ guia/custosfinanceiros/taxa-juros-longo-prazo-tjlp $>$ Acesso em 01 mai. 2018.

BRASIL. LEI No 10.194, de 14 de fevereiro de 2001. Disponível em:

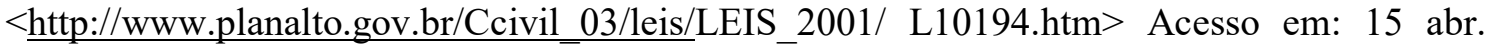
2018. 
CAVALCANTI, Glauco; TOLOTTI, Marcia. Empreendedorismo: Decolando para o futuro. Rio de Janeiro: Elsevier: SEBRAE, 2011.

DOWBOR, Ladislau. Os estranhos caminhos do nosso dinheiro. São Paulo: Fundação Perseu Abramo, 2013.

FICHE, Marcelo Estrela. Spread bancário no Brasil. 2015. 65 f., il. Tese (Doutorado em Economia) - Universidade de Brasília, Brasília, 2015. Disponível em:

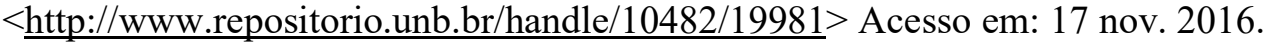

GASTALDI, J. Petrelli. Elementos de economia política, 19. ed. São Paulo: Saraiva, 2006. GUILHERME MAZUI. Governo prepara bolsa para incentivar saída de beneficiários do Bolsa Família. G1. Disponível em: <https://g1.globo.com/politica/noticia/governo-preparaprograma-para-incentivar-saida-de-beneficiarios-do-bolsa-familia.ghtml > Acesso em 30 mai. 2018.

KEYNES, J. M. (1936). A teoria geral do emprego, do juro e da moeda. São Paulo: Saraiva, 2012.

MARQUES, A.; FACHADA, P.; CAVALCANTI, D. Sistema Banco Central de Expectativas de Mercado. Nota Técnica n. 36. Banco Central do Brasil, 2003.

MARTINS, Pedro Ribeiro. A Constituição dos Atenienses. [S.1.]: 2013. Disponível em: $<$ https://digitalis-dsp.uc.pt/bitstream/10316.2/2392/7/pseudo\%20xenofonte.pdf $>$ Acesso em: 17 nov. 2016.

MENDONÇA, Helder Ferreira. Mecanismos de transmissão monetária e a determinação da taxa de juros: uma aplicação da regra de Taylor ao caso brasileiro. Economia e Sociedade, Campinas, 2001. Disponível em: $<$ https://periodicos.sbu.unicamp.br/ojs/index.php/ecos/article/download/8643105/10656. $>$ Acesso em: 17 nov. 2016.

MONEYOU. Ranking Mundial de Juros Reais. Jan/16. Disponível em: $<$ http://moneyou.com.br/wpcontent/uploads/2016/01/rankingdejurosreais190116.pdf $>$

Acesso em: 05 abr. 2017.

MOREIRA, Talita. Brasil tem spread bancário mais elevado entre 12 países. Valor Econômico. Disponível em: <http://www.valor.com.br/financas/5143306/brasil-tem-spreadbancario-mais-elevado-entre-12-paises-mostra-estudo $>$ Acesso em 04 out. de 2017. PEREIRA, Luiz Carlos Bresser. Economia e Administração: Mercado e poder. Disponível em: <http://www.scielo.br/scielo.php?script=sci_arttext\&pid=S0034-75901979000400003> Acesso em 17 nov. 2016. 
PORTAL DO EMPREENDEDOR. Estatísticas. Disponível em: < $\underline{\text { http://www. }}$ portaldoempreendedor.gov.br/estatisticas > Acesso em 01 mai. 2018.

PORTAL DO EMPREENDEDOR. Soluções financeiras para o seu negócio. Disponível em $<$ http://www.portaldoempreendedor.gov.br/temas/ja-sou/servicos/acesso-a-servicosfinanceiros/solucoes-financeiras-para-o-seu-negocio > Acesso em 01 mai. 2018.

PORTAL FEBRABAN. Estudo do spread bancário. Disponível em: $<\underline{\text { https://cmsportal.febraban.org.br/Arquivos/documentos/PDF/Estudo } \% 20 \mathrm{do} \% 20 \mathrm{Spread} \% 20}$ Banc\%C3\%A1rio_out_17.pdf> Acesso em 01 jun. 2018 PORTAL FEBRABAN. FEBRABAN propõe reforma do ambiente de crédito para reduzir

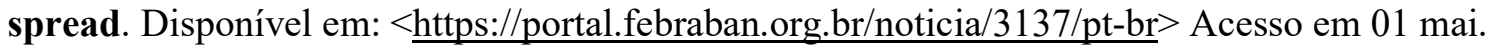
2018.

QUEIROZ, M. F. Gerenciamento das reservas bancárias: risco de contágio, previsibilidade e expectativas. 2004. Tese (Doutorado em Economia) - Universidade de Brasília, Brasília, $2004 . \quad$ Disponível em:

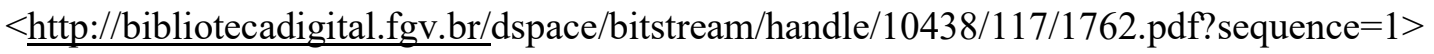
Acesso em: 17 nov. 2016.

REVISTA PEQUENAS EMPRESAS, GRANDES NEGÓCIOS. Sebrae-SP lança linha de crédito com juros zero para microempreendedores. Disponível em: $<\underline{\text { https://revistapegn.globo.com/Feira-do-Empreendedor-SP/noticia/2017/01/sebrae-sp-lanca- }}$ linha-de-credito-com-juro-zero-para-microempreendedores.html> Acesso em 19 abr. 2018.

SANTOS, Jonábio Barbosa dos; SOUSA, Nathália Guerra de. Falência e recuperação de empresas: contribuição para a materialização da função social. Disponível em: $<\underline{\text { http://www.esmarn.tjrn.jus.br/revistas/index.php/revista direito e _ _ liberdade }}$ /article/view/759/657> Acesso em: 05 abr. 2017.

SEBRAE. Micro e pequenas empresas geram 27\% do PIB do Brasil. Disponível em: http://www.sebrae.com.br/sites/PortalSebrae/ufs/mt/noticias/micro-e-pequenas-empresasgeram-27-do-pib-do-brasil,ad0fc70646467410VgnVCM2000003 c74010aRCRD> Acesso em 17 nov. 2016.

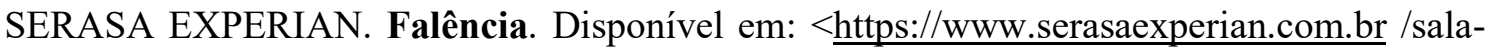
de-imprensa/pedidos-de-falencias-caem-166-no-ano-revela-serasa-experian> Acesso em: 17 nov. 2016. 
SILVA, José Pereira da. Análise financeira das empresas. 3. ed. São Paulo: Atlas, 1995.

SILVA, Maria Adriana. Entrevista concedida à Natalie Burgardt Ferreira. São Paulo, 21 de maio 2017. 